\title{
Evaluation of the Ogawa-Kudoh method for tuberculosis isolation in two health units in Mozambique
}

\begin{tabular}{|c|c|}
\hline $\begin{array}{l}\text { Authors: } \\
\text { Carla M. Made } \\
\text { Khalide I. Azan } \\
\text { Daisy N. Sato } \\
\text { Celso Khosa } \\
\text { Nilesh Bhatt } \\
\text { Sofia O. Viegas }\end{array}$ & $\begin{array}{l}\text { eira }{ }^{1} \text { (D) } \\
n^{1} \text { (D) } \\
\text { (D) } \\
0 \\
0 \\
0\end{array}$ \\
\hline $\begin{array}{l}\text { Affiliations: } \\
{ }^{1} \text { National Tube } \\
\text { Reference Lab } \\
\text { Instituto Nacic } \\
\text { Marracuene, N }\end{array}$ & $\begin{array}{l}\text { erculosis } \\
\text { oratory, } \\
\text { onal de Saúde, } \\
\text { Mozambique }\end{array}$ \\
\hline $\begin{array}{l}{ }^{2} \text { American Soc } \\
\text { Microbiology, } \\
\text { Brazil }\end{array}$ & $\begin{array}{l}\text { iety for } \\
\text { São Paulo, }\end{array}$ \\
\hline $\begin{array}{l}{ }^{3} \text { Centro de Inv } \\
\text { Treino em Saú } \\
\text { Caniço, Institu } \\
\text { Saúde, Marrac } \\
\text { Mozambique }\end{array}$ & $\begin{array}{l}\text { estigação e } \\
\text { de da Polana } \\
\text { to Nacional de } \\
\text { cuene, }\end{array}$ \\
\hline $\begin{array}{l}{ }^{4} \text { Department } \\
\text { Laboratory Ne } \\
\text { Reference Ser } \\
\text { Nacional de Sa } \\
\text { Marracuene, }\end{array}$ & $\begin{array}{l}\text { f the } \\
\text { twork and } \\
\text { vices, Instituto } \\
\text { aúde, } \\
\text { Mozambique }\end{array}$ \\
\hline $\begin{array}{l}\text { Correspondin } \\
\text { Sofia Viegas, } \\
\text { viegas_sofia@ }\end{array}$ & $\begin{array}{l}\text { g author: } \\
\text { hotmail.com }\end{array}$ \\
\hline $\begin{array}{l}\text { Dates: } \\
\text { Received: } 30 \\
\text { Accepted: } 07 \\
\text { Published: } 20\end{array}$ & $\begin{array}{l}\text { apt. } 2018 \\
\text { Apr. } 2020 \\
\text { July } 2020\end{array}$ \\
\hline $\begin{array}{l}\text { How to cite th } \\
\text { Madeira CM, } \\
\text { Sato DN, Khos } \\
\text { Viegas SO. Eva } \\
\text { Ogawa-Kudoh } \\
\text { tuberculosis is } \\
\text { health units in } \\
\text { Afr J Lab Med. } \\
\text { a929 https://d } \\
\text { 10.4102/ajlm. }\end{array}$ & $\begin{array}{l}\text { is article: } \\
\text { Azam KI, } \\
\text { a C, Bhatt N, } \\
\text { luation of the } \\
\text { method for } \\
\text { olation in two } \\
\text { Mozambique. } \\
2020 ; 9(1) \text {, } \\
\text { oi.org/ } \\
\text { vi1.929 }\end{array}$ \\
\hline Read online: & \\
\hline 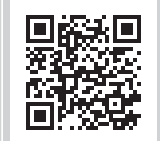 & $\begin{array}{l}\text { Scan this QR } \\
\text { code with your } \\
\text { smart phone or } \\
\text { mobile device } \\
\text { to read online. }\end{array}$ \\
\hline
\end{tabular}

Background: Mozambique is among the highest tuberculosis, tuberculosis-HIV and multidrug-resistant-tuberculosis burden countries. Although molecular technologies are available in-country, mycobacterial isolation through culture remains an important tool for tuberculosis diagnostics and drug susceptibility testing.

Objective: We evaluated the use of the Ogawa-Kudoh (OK) mycobacterial culture, a simple technique, to isolate Mycobacterium tuberculosis in two health units, in Maputo City, Mozambique.

Methods: From May to December 2014, 122 patient samples were collected in Chamanculo General Hospital and Polana Caniço General Hospital. The specimens were first tested in the health units using the OK method and afterwards shipped to the National Tuberculosis Reference Laboratory for mycobacterial culture using the NALC-NaOH-Citrate (NALC) decontamination method followed by inoculation in Lowenstein Jensen (LJ) solid media as the reference standard.

Results: Among 107 samples with valid results, 98 (91.6\%) had concordant results in both methods; 9 (8.4\%) had discordant results. The contamination rate was $4.1 \%(5 / 122)$ for the OK and $9.0 \%(11 / 122)$ for the NALC/LJ methods. The sensitivity of OK was $80 \%(95 \%$ confident interval [CI]: 51.4-94.7) and the specificity was 94\% (95\% CI: 85.8-97.3). The degree of agreement between both methods was moderate (Kappa: 0.68; 95\% CI: 0.48-0.89).

Conclusion: The OK method showed satisfactory sensitivity and specificity. The method also had a lower contamination rate when compared to the NALC/LJ. Similar to other studies in resource-limited settings, our findings showed that the OK method can effectively be implemented in settings with limited laboratory capacity to isolate tuberculosis bacteria by culture for further testing.

Keywords: Ogawa-Kudoh; mycobacterial culture; tuberculosis diagnostics; Mozambique; laboratory.

\section{Introduction}

Mozambique is amongst the highest tuberculosis, tuberculosis-HIV and multidrug-resistanttuberculosis burden countries. ${ }^{1}$ At present, the country has a tuberculosis laboratory network comprised of three tuberculosis reference laboratories, 85 sites performing Xpert ${ }^{\circ}$ MTB/RIF (Cepheid, Sunnyvale, California, United States) and 400 smear microscopy laboratories. Mycobacterial culture is only performed in the three tuberculosis reference laboratories, using both solid Lowenstein Jensen (LJ) media and liquid mycobacterial growth indicator tubes for simultaneous analysis. The national testing algorithm recommends mycobacterial culture for Xpert ${ }^{\circledR}$ MTB/RIF-resistant cases and for treatment monitoring of resistant cases in order to isolate Mycobacterium tuberculosis for further drug susceptibility testing. Mycobacterial culture is considered the reference standard for tuberculosis diagnosis. However, one of its major constraints is sample transportation from the collection site to the reference laboratory. In most cases, long transportation distances are associated with the need for a cold chain, prompting high contamination rates in the presence of fast-growing bacteria, and that can lead to under-diagnosis of tuberculosis.

Another constraint on the performance of mycobacterial cultures is the need for high-level containment laboratories, because of testing procedures, and the need for qualified

Copyright: ( 2020. The Authors. Licensee: AOSIS. This work is licensed under the Creative Commons Attribution License. 
laboratory staff. ${ }^{2,3,4}$ These requirements come with high costs, which contribute to challenges associated with implementing mycobacterial culture in rural areas. ${ }^{4}$

In order to detect and treat all tuberculosis cases, it is necessary to expand simple and accessible diagnostic laboratory services, especially in resource-limited countries such as Mozambique. In 1974, Kudoh and Kudoh described a simple, rapid and inexpensive mycobacterial culture method, the Ogawa- Kudoh (OK) method, ${ }^{5}$ which does not require high-level laboratory containment or extensive technical training. ${ }^{5}$ Evaluating the applicability of the OK mycobacterial method opens up the possibility for less specialised laboratories to carry out tuberculosis culture, increasing the diagnosis capacity in the country. The aim of this study was to evaluate the accuracy and applicability of the OK method, as compared to LJ mycobacterial culture as the reference standard, for M. tuberculosis isolation in two peri-urban health units in Maputo City, Mozambique.

\section{Methods}

\section{Ethical considerations}

Ethical approval to conduct the study was obtained from the National Bioethics Committee (CNBS), Ministry of Health, Mozambique, with the reference number 368/ CNBS/13. The patients were included after understanding the study procedures and signing a written informed consent form.

\section{Study setting}

The study was conducted in two health units in Maputo City, Chamanculo General Hospital and Polana Caniço General Hospital. Both are level II health units, located in peri-urban areas of Maputo. The distance from the National Tuberculosis Reference Laboratory in Maputo to Chamanculo General Hospital is $4.5 \mathrm{~km}$ and to Polana Caniço General Hospital is $2.3 \mathrm{~km}$. At the time of the evaluation, both laboratories were only performing tuberculosis diagnosis by smear microscopy. Requests for mycobacterial cultures from the two health units were sent to the National Tuberculosis Reference Laboratory in Maputo.

\section{Patients and specimens}

This cross-sectional study was conducted between May 2014 and December 2014. A total of 122 samples, one per patient, categorised as new (i.e. patients with presumptive pulmonary tuberculosis who had never been treated for tuberculosis or had been treated for less than 30 days) or previously-treated (i.e. patients with presumptive pulmonary tuberculosis who had been treated for tuberculosis for more than 30 days), were consecutively included in the study. The specimens were first tested in the health units using the OK method and the remaining samples were shipped to the National Tuberculosis Reference Laboratory in Maputo for mycobacterial culture using the N-acetyl-L-cysteine (NALC)sodium hydroxide $(\mathrm{NaOH})$-citrate decontamination method, followed by inoculation in LJ solid media, which was used as a reference standard. Auramine-O staining was also performed at Chamanculo General Hospital, and a ZiehlNielsen smear microscopy was performed at Polana Caniço General Hospital.

A 5-day training schedule was performed for laboratory technicians from the two health units, which also included biosafety and OK technical training. Staff technical competency was also evaluated. Standard operational procedures and registration forms were implemented for the study and supervision visits were performed once a week at each participating site. Basic patient demographics were collected from laboratory request forms.

\section{Ogawa-Kudoh method}

The OK method was performed as described by Kudoh and Kudoh. ${ }^{5}$ Briefly, sputum samples were impregnated in a swab. The impregnated swab was placed in a sterile tube containing $3 \mathrm{~mL}$ of $4 \% \mathrm{NaOH}$ solution for 2 minutes and then inoculated with rotary movements in the $\mathrm{OK}$ media. Mycobacterial cultures were incubated at $36 \pm 1{ }^{\circ} \mathrm{C}$ for up to 60 days.

\section{NALC-NaOH-Citrate/LJ method}

Equal volumes of sputum sample and NALC-NaOH-citrate reagent were added to a $50 \mathrm{~mL}$ conical tube, after which the mixture was stirred and allowed to stand for $15 \mathrm{~min}$ at room temperature. After $15 \mathrm{~min}, 35 \mathrm{~mL} 0.067 \mathrm{M}$ phosphate buffer ( $\mathrm{pH}$ 6.8) was added to the mixture. The mixture was then mixed by inversion and centrifuged at $3000 \mathrm{~g}$ for $15 \mathrm{~min}$. The supernatant was discarded and the pelleted material was resuspended in $1 \mathrm{~mL}$ of buffer. From the suspension, $0.5 \mathrm{~mL}$ was inoculated into solid LJ medium and incubated at $37^{\circ} \mathrm{C}$ for up to 8 weeks. Tubes were read weekly to verify the presence of mycobacteria. ${ }^{6}$

The use of LJ as the reference standard method, instead of the liquid mycobacterial growth indicator tube culture, which had higher sensitivity and higher contamination rates when compared to LJ, was made in order to establish a direct comparison between the two solid media methods (OK and LJ). A smear microscopy examination of the suspension was also performed.

\section{Statistical analyses}

The culture contribution to diagnostics was calculated based on the recovery rate for both methods, $\mathrm{OK}$ and $\mathrm{LJ}$, as the ratio between positive cultures and negative smear microscopy. A database was created in Microsoft Office Access (2007, Version 12; Microsoft Corp, Redmond, Washington, United States), and was later exported to IBM SPSS Statistics for Windows (2015, version 23.0; IBM Corp., Armonk, New York, United States) for analysis of sensitivity, specificity, predictive values (positive and negative) and the degree of agreement between the methods. Concordance between the tests was 
TABLE 1: Comparison between Ogawa-Kudoh and NALC-NaOH/Lowenstein Jensen methods, Mozambique, 2014.

\begin{tabular}{|c|c|c|c|c|c|c|c|c|c|c|c|c|c|c|c|}
\hline \multirow[t]{3}{*}{ OK Method } & \multicolumn{5}{|c|}{ NALC-NaOH/L } & \multicolumn{2}{|c|}{ PPV } & \multicolumn{2}{|c|}{ NPV } & \multicolumn{2}{|c|}{ Sensitivity } & \multicolumn{2}{|c|}{ Specificity } & \multicolumn{2}{|c|}{$\begin{array}{l}\text { Kappa index } \\
\text { (concordance) }\end{array}$} \\
\hline & \multicolumn{2}{|c|}{ Positive } & \multicolumn{2}{|c|}{ Negative } & \multirow[t]{2}{*}{ Total } & \multirow[b]{2}{*}{$\%$} & \multirow[b]{2}{*}{$95 \% \mathrm{Cl}$} & \multirow[b]{2}{*}{$\%$} & \multirow[b]{2}{*}{$95 \% \mathrm{Cl}$} & \multirow[b]{2}{*}{$\%$} & \multirow[b]{2}{*}{$95 \% \mathrm{Cl}$} & \multirow[b]{2}{*}{$\%$} & \multirow[b]{2}{*}{$95 \% \mathrm{Cl}$} & \multirow[b]{2}{*}{$n$} & \multirow[b]{2}{*}{$95 \% \mathrm{Cl}$} \\
\hline & $n$ & $\%$ & $n$ & $\%$ & & & & & & & & & & & \\
\hline Positive & 12 & 11.2 & 6 & 5.6 & 18 & 667 & $412-856$ & 966 & ८9 ৪-99 1 & 80 & $514-947$ & 935 & $858-973$ & 068 & $048-089$ \\
\hline Negative & 3 & 2.8 & 86 & 80.4 & 89 & 66.1 & $41.2-85.6$ & 96.6 & $89.8-99.1$ & 80 & $51.4-94.1$ & 93.5 & $85.8-9 / .3$ & 0.68 & $0.48-0.89$ \\
\hline Total & 15 & - & 92 & - & $107 \dagger$ & & & & & & & & & & \\
\hline
\end{tabular}

OK, Ogawa-Kudoh; L, Lowenstein Jensen; PPV, Positive Predictive Value; NPV, Negative Predictive Value.

$\dagger$, Excluding contamination in both methods; $n=15$

analysed using the Friedman Kappa test. To verify whether there were associations between the performance of the methods, and the demographic characteristics and categories of patients, the Chi-square test was performed.

The level of statistical significance was set to 0.05 (two-sided) for all analyses. Formulas to calculate sensitivity, specificity, positive predictive value, and negative predictive value were used as previously described. ${ }^{7}$ Levels of agreement were interpreted as follows: values greater than or equal to 0.75 were interpreted as having 'excellent' concordance between the two variables; values between 0.4 and 0.75 , 'sufficient to good' agreement; and values smaller than 0.40, 'weak' agreement.

\section{Results}

Of the 122 samples analysed, 60 were from female patients and 62 were from male patients. The median age was 36 years (range:8-70 years). Regarding the category of the patients, most cases had previously been treated $(n=84$, $68.9 \%$ ) and 38 cases were new (31.1\%) (data not shown in tables).

A total of 98 (80.3\%) patients had concordant culture results for both methods, 9 (7.4\%) had discordant results and 15 (12.3\%) had contaminated results (10 samples were contaminated on LJ only, 4 contaminated on OK only, and 1 was contaminated on both methods). The contamination rate for OK was $4.1 \%$ $(5 / 122)$ and for NALC/LJ, 9.0\% (11/122).

Against the NALC/LJ method as the reference standard, and excluding contaminated results, the sensitivity of the OK method was $80 \%(12 / 15 ; 95 \%$ CI: 51.4-94.7), the specificity was $93.5 \%(86 / 92 ; 95 \%$ CI: 85.8-97.3), the proportion of patients with true-negative results in both techniques was $96.6 \%$ (86/89; 95\% CI: 89.9-99.1), and the proportion of patients with true-positive results using both techniques was $66.7 \%(12 / 18 ; 95 \%$ CI: $41.2-85.6)$. The agreement between the two methods was Kappa $=0.68(95 \%$ CI: 0.48-0.89) (Table 1).

For the comparison between the two culture methods, contaminated results were also excluded from the analysis. Mycobacterial culture positivity was 17/111 (15.3\%) for NALC/LJ and 18/117 (15.4\%) for the OK method. The recovery rate was similar for both methods, $17.1 \%(18 / 105)$ for OK and 17.9\% (17/95) for LJ (Tables 2 and 3).
TABLE 2: Results ratio of mycobacterial culture and direct microscopy, Mozambique, 2014. $\dagger$

\begin{tabular}{|c|c|c|c|c|c|c|}
\hline \multirow{3}{*}{$\begin{array}{l}\text { Ogawa Kudoh method, } \\
\text { Health Unit }\end{array}$} & \multicolumn{6}{|c|}{ Ogawa Kudoh result } \\
\hline & \multicolumn{2}{|c|}{ Negative } & \multicolumn{2}{|c|}{ Positive } & \multicolumn{2}{|c|}{ Total } \\
\hline & $n$ & $\%$ & $n$ & $\%$ & $n$ & $\%$ \\
\hline \multicolumn{7}{|l|}{ Sputum smear } \\
\hline Positive & 95 & 81.2 & 10 & 8.5 & 105 & 89.7 \\
\hline Negative & 4 & 3.4 & 8 & 6.8 & 12 & 10.3 \\
\hline Total & 99 & 84.6 & 18 & 15.4 & 117 & 100.0 \\
\hline
\end{tabular}

$\dagger$, Excluding contamination in both methods, $n=15$.

TABLE 3: Results ratio of mycobacterial culture and direct microscopy, Mozambique, 2014. $\dagger$

\begin{tabular}{|c|c|c|c|c|c|c|}
\hline \multirow{3}{*}{$\begin{array}{l}\text { NALC/LJ method, } \\
\text { National Tuberculosis } \\
\text { Reference Laboratory }\end{array}$} & \multicolumn{6}{|c|}{ NALC/LJ result } \\
\hline & \multicolumn{2}{|c|}{ Negative } & \multicolumn{2}{|c|}{ Positive } & \multicolumn{2}{|c|}{ Total } \\
\hline & $n$ & $\%$ & $n$ & $\%$ & $n$ & $\%$ \\
\hline \multicolumn{7}{|l|}{ Sputum smear } \\
\hline Positive & 93 & 83.8 & 2 & 1.8 & 95 & 85.6 \\
\hline Negative & 1 & 0.9 & 15 & 13.5 & 16 & 14.4 \\
\hline Total & 94 & 84.7 & 17 & 15.3 & 111 & 100.0 \\
\hline
\end{tabular}

ᄂ, Lowenstein Jensen.

$\dagger$, Excluding contamination in both methods, $n=15$.

\section{Discussion}

In this study, sensitivity, specificity, positive predictive value and negative predictive value were acceptable for the OK method. In addition, there was a high degree of agreement and the recovery rate was similar between the $\mathrm{OK}$ and NALC/LJ methods. The contamination rate of the NALC/LJ method was twice as high as the OK method. This finding reinforces the capacity of OK to kill other contaminants, since the OK media is slightly more acidic compared to LJ and neutralises the high concentration of $\mathrm{NaOH}$ used to decontaminate the sample. Similar studies performed in Brazil (in 1999, 2006, and 2018) and Peru (in 2007) also found significant differences between the contamination rates obtained with OK and with standard mycobacterial culture methods, again showing that the OK method is efficient in recovering mycobacteria and efficiently killing contaminants. ${ }^{8,9,10,11}$ These results indicate the value of the OK mycobacterial method for diagnosis of pulmonary tuberculosis as a possible alternative for the NALC/LJ method.

The OK mycobacterial method has been used successfully in other countries, particularly in Latin America, including Brazil, as an alternative to traditional culture methods. ${ }^{4,12,13}$ The Pan-American Health Organization recommends the use of OK for tuberculosis diagnosis in areas with limited laboratory capacity. ${ }^{14} \mathrm{~A}$ study conducted in Uruguay, with 
the purpose of assessing the efficacy of the OK method for mycobacterial culture in sputum samples, found that after conserving and shipping specimens at room temperature without the addition of any substances to prevent the overgrowth of contaminating bacteria, the OK method was appropriate for culturing mycobacteria, even when processing was delayed for 2-4 days from collection. ${ }^{15}$ Furthermore, the study showed that the duration of the decontamination time was not critical and satisfactory outcomes can still be obtained by increasing the decontamination time up to $4 \mathrm{~min} .{ }^{15}$

In general, mycobacterial culture on LJ, when performed on sputum samples, generates approximately 20\% more positives than smear microscopy, ${ }^{4}$ because the sensitivity of smears is lower when compared to culture. Access to mycobacterial culture is a challenge in Mozambique, since there are only three tuberculosis reference laboratories, some health units are hard to access by road, the distances are long and the laboratory capacity is limited. Additionally, Mozambique is a tropical country, where the temperature can reach $40{ }^{\circ} \mathrm{C}$ during summer. The sample transport system is very mixed and relies on motorbikes, bicycles, ambulances or partners, and samples are not shipped daily. All of these factors contribute to delays in samples reaching the reference laboratories and to sample contamination, leading to inconclusive results.

Although advanced molecular methods, such as the Xpert ${ }^{\circledR}$ MTB/RIF, are available in Mozambique, mycobacterial culture remains the reference standard for tuberculosis diagnosis. Furthermore, culture is needed to isolate the bacteria for other tests, including drug susceptibility tests and sequencing in this environment of increasing resistance to tuberculosis drugs. The mycobacterial culture using the OK method is a simple-to-perform, low-cost method and its biosafety requirements present a lower risk to laboratory technicians, since it does not require agitation or centrifugation steps, and thus reduces the production of aerosols. However, establishment of this assay in peripheral laboratories requires biosafety training and awareness of the risks and precautions for manipulation of Class III pathogens. Additionally, triple packing biosafety procedures must be implemented to ship positive samples from these laboratories to reference laboratories for further diagnostic assays, such as identification of the M. tuberculosis complex and drug susceptibility tests.

\section{Limitations}

The present study was conducted at only two health facilities in Maputo City, which might not provide the study with the power to generalise the findings. In addition, there may have been delays in shipping samples from the Health Centres to the National Tuberculosis Reference Laboratory in Maputo, as a result of transportation constraints. This can affect the quality of the specimen, allowing the growth of other bacteria and leading to contamination. Liquid (mycobacterial growth indicator tube) culture results were not evaluated, and were not compared with the OK or LJ mycobacterial culture methods. Liquid culture is known to have higher sensitivity, and could have had implications for the OK or LJ findings. Re-decontamination and re-inoculation of the contaminated tubes, to increase valid results and to reduce contamination rates, was not considered for the present study.

\section{Conclusion}

The OK method showed satisfactory sensitivity and specificity, with lower contamination rates and higher detection rates when compared to the NALC/LJ method. The OK method can effectively be implemented in settings with limited laboratory capacity to isolate tuberculosis bacteria by culture for further testing.

\section{Acknowledgements}

The authors acknowledge the National Tuberculosis Reference Laboratory staff for their support during the study and their commitment to improve tuberculosis diagnosis in Mozambique.

\section{Competing interests}

The authors declare that they have no financial or personal relationships that may have inappropriately influenced them in writing this article.

\section{Authors' contributions}

C.M.M. conceived the study design, performed the laboratory tests, and wrote the first draft of the article. K.I.A. supervised the laboratory work and supported the data analysis. D.N.S. and S.O.V. provided general supervision during the study implementation and reviewed the manuscript draft. C.K. and N.B. participated in the data analysis, reviewed the draft and provided writing support. All authors gave final approval of the version to be published and agree to be accountable for the accuracy and integrity of the work.

\section{Sources of support}

None.

\section{Data availability statement}

Data sharing is not applicable to this article as no new data were created or analysed in this study.

\section{Disclaimer}

The views expressed in the submitted article are the authors' own and not an official position of the institution or funder.

\section{References}

1. World Health Organization. 2018. Global tuberculosis report 2018. World Health Organization. Geneva, Switzerland. 
2. European Centre for Disease Prevention and Control. Handbook on tuberculosis laboratory diagnostic methods in the European Union - Updated 2018 [https:// ecdc.europa.eu]. Stockholm: ECDC, 2018;p. 115. [cited 2019 May 23]; Available ecdc.europa.eu]. Stockholm: ECDC, 2018;p. 115. [cited 2019 May 23]; Available from: hal.pdf

3. World Health organization. Implementing tuberculosis diagnostics. Policy framework [https://www.who.int]. 2015. [cited 2016 February 18]; Available from: https://www.who.int/tb/publications/implementing_TB_diagnostics/en/

4. Ministério da Saúde, Secretaria de Vigilância em Saúde, Departamento de Vigilância Epidemiológica. Manual Nacional de Vigilância Laboratorial da Tuberculose e outras micobactérias. 1a Edição. Brasília, 2008;p. 436.

5. Kudoh S, Kudoh T. A simple technique for culturing tubercle bacilli. 1974;51(1):71-82.

6. Kubica GP, Dye WE, Cohn ML, Middlebrook G. Sputum digestion and decontamination with $\mathrm{N}$-acetyl-L-cysteine-sodium hydroxide for culture of mycobacteria. Am Rev Respir Dis. 1963;87(5):775-779.

7. Pestana MH, Gageiro JN. Análise de Dados para Ciências Sociais - A Complementariedade do SPSS [https://www.researchgate.net]. 6th ed. Lisbon; 2014. [cited 2015 January 28]; Available from: https://www. researchgate.net/publication/272817141_ANALISE_DE_DADOS_PARA CIENCIAS_SOCIAIS_A_Complementaridade_do_SPSS_6_EDICAO_Revista_ Atualizada_e_Aumentada_MARIA_HELENA_PESTANA_JOAO_NUNES GAGEIRO

8. Coelho AG, Zamarioli LA, Vicente MP, Reffo e Silva R. Avaliaçäo do método de Ogawa: Kudoh para o isolamento de micobactérias/Evaluation of the Ogawa: Kudoh method for the isolation of mycobacteria. Rev Inst Adolfo Lutz. 1999;2(58):57-61.
9. Parimango Rodríguez D, Chávez Castillo $M$, Luján Velásquez $M$, Otiniano García $M$ Robles Castillo H, Muñoz Ganoza E. Comparación de los medios Ogawa y
Löwenstein Jensen en el aislamiento de Mycobacterium tuberculosis de pacientes con tuberculosis pulmonar. Hospital Regional Docente de Trujillo, Perú. Rev Med con tuberculosis pulmonar. Hospital Regional Docente de Trujillo, Perú. Rev Med
Vallejiana. 2007;4(1):24-31. https://doi.org/10.18050/revistamedicavallejiana. Vallejiana.

10. Jaspe RC, Rojas YM, Flores LA, Sofia Toro E, Takiff H, De Waard JH. Evaluation of the Kudoh swab method for the culturing of Mycobacterium tuberculosis in rural areas. Trop Medint 3156.2009.02236.x

11. Costa RR da, Silva SF da, Fochat RC, et al. Comparison between Ogawa-Kudoh and modified Petroff techniques for mycobacteria cultivation in the diagnosis of pulmonary tuberculosis. Einstein (São Paulo) [www.scielo.br]. 2018 [cited 2019 May 23]; 16(2). Available from: http://www.scielo.br/scielo.php?script=sci arttext\&pid=S1679-45082018000200209\&/ng=en\&tlng=en

12. Aily DCG, Shikama M de LM, Oliveira MLF, Silva RM. Perfil bacteriológico da tuberculose pulmonar na região de Campinas e das Diretorias Regionais de Saúde XII, XV e XX - 1999/2000. Rev Inst Adolfo Lutz. 2003;62(1):5-10.

13. Borges M, Cafrune PI, Possuelo LG, Valim AR de M, Ribeiro MO, Rossetti MLR Análise molecular de cepas de Mycobacterium tuberculosis provenientes de um centro de saúde ambulatorial em Porto Alegre, (RS). J BrasPneumol. 2004;30(4):358-364.https://doi.org/10.1590/S1806-37132004000400010

14. Organización Panamericana de la Salud. Manual para el diagnóstico bacteriológico de la tuberculosis parte II - CULTIVO [https://www.paho.org/en]. 2008, 107 p [Acessed on January 19, 2015]; Available from: http://www1.paho.org/Spanish/ $\mathrm{AD} / \mathrm{DPC} / \mathrm{CD} / \mathrm{tb}$-labs-cultivo.pdf.

15. Rivas C, Coitinho C, Dafond V, Corbo M, Baldjian M. Performance of the OgawaKudoh method for isolation of mycobacteria in a laboratory with large-scale workload. Rev ArgentMicrobiol. 2010;42(2):87-90. 